\title{
Clinical observation of extensive fascial resection combined with autologous limbal stem cell sharing transplantation for treatment of pterygium
}

\section{Wen-Jia Zhang}

Second people hospitai Yunnan Prpvonce

Lei Kong

Second people hospital Yunnan province

\section{Xiao-Xiao Feng}

Second people hospital Yunnan province

Ji Yang

Second people hospital Yunnan province

Hai Liu

Second people hospital Yunnan province

\section{Hong-Qin Ke}

Second people hospital Yunnan province

\section{Qian Zhang}

Second people hospital Yunnan province

\section{Yin-Ting Wang}

Second people hospital Yunnan province

Yan Li

Second people hospital Yunnan province

Zhulin Hu ( $\sim$ hzl77@263.net)

Kunming medical university https://orcid.org/0000-0002-1575-5356

\section{Research article}

Keywords: Extensive fascial resection, autologous limbal stem cells, shared transplantation, pterygium

Posted Date: April 14th, 2020

DOI: https://doi.org/10.21203/rs.3.rs-20920/v1

License: (1) (1) This work is licensed under a Creative Commons Attribution 4.0 International License.

Read Full License 


\section{Abstract}

Introduction To observe the short-term and long-term effects of extensive fascial resection combined with autologous limbal stem cell sharing transplantation for pterygium.

Methods A retrospective case series analysis was performed with 403 patients (420 eyes) who underwent extensive fascial resection combined with autologous limbal stem cell sharing transplantation in the Department of Ophthalmology, Second People's Hospital of Yunnan Province from January 2017 to June 2018. Before, and 10 days, 1 month, 3 months, and 6 months after surgery, the tear film rupture time (BUT), the height of the tear river (SLT), and the anterior segment of the fluoroscopy staining were recorded to record the scar on the conjunctiva and corneal surface. Patient self-consciousness and satisfaction with the appearance of the survey.

Results BUT after surgery was prolonged than before operation, and there was no significant difference in tear height preoperative and postoperative. The postoperative follow-up period ( 6 months), the recurrence rate of pterygium was $0.21 \%$.Patients have higher satisfaction with appearance, and have no obvious foreign body sensation, photophobia, tearing and other subjective symptoms.

Discussion and conclusion Extensive fascial resection combined with autologous limbal stem cell sharing transplantation for the treatment of pterygium, the patient's appearance satisfaction is higher, and the recurrence probability is lower than the average recurrence rate of limbal stem cell transplantation. The operation is simple and easy to learn. This is a surgical procedure worth promoting.

\section{Introduction}

Pterygium is a non-malignant, slow-growing conjunctival fibrous vascular tissue of the conjunctiva. Pterygium extends to cover the cornea, which can cause significant irregular corneal astigmatism, pupil occlusion and affect visual acuity. It can also cause eye discomfort and dry eyes[1]. In worldwide, the prevalence rate of pterygium varies greatly among different study groups, ranging from $1-25 \%[2,3]$. The prevalence rate of Han nationality over 50 years old in Yunnan Province of China is even as high as $39.5 \%[4]$. The risk of pterygium is associated with advanced age, men, low education, outdoor work, and rural areas[5]. Ultraviolet radiation, high temperature, dusty, dry and smoked environment can all be the risk factors of pterygium. The size of pterygium is positively correlated with the time of outdoor work[6].

The pathogenesis of pterygium is not completely clear, previous research has found that the lack of limbal stem cells was closely related to the occurrence and recurrence of pterygium[7, 8]. At the same time, some studies have shown that, the conjunctival epithelial cells of pterygium tissue are over proliferated, and some cells at the base of the epithelial base are long fusiform, similar to fibroblasts, and the cells are distributed in groups[9]. The basal surface of the cells break through the basement membrane and infiltrates and grows into the matrix. The loose connective tissue under the epithelium contains a large number of fibroblasts and abundant capillaries, which indicates that the pterygium epithelial cells have a strong ability to proliferate and migrate. Some of the fibroblasts in the loose 
connective tissue of the sub-epithelium may come from the epithelial cells that undergo the conversion from epithelial cells to mesenchymal cells (epithelial-mesenchymal transition, EMT)[10]. After surgical treatment of pterygium, there will still be a small number of mutant epithelial stem cells remaining. The activation and proliferation of residual stem cells may be an important factor in the recurrence of pterygium after operation[11].

Surgical excision is the main treatment of pterygium, but the postoperative recurrence rate is high, the appearance of the eye is not ideal, postoperative foreign body feeling has been a difficult problem of clinical treatment. At present, there are many surgical methods for pterygium, including simple pterygium excision. Pterygium excision combined with autologous conjunctival flap transposition, pterygium excision combined with amniotic membrane transplantation, pterygium excision combined with autologous limbal stem cell transplantation and so on ${ }^{[12]}$. Simple pterygium excision only excises of pterygium head and neck after direct suture wound, although the operation is simple, but the postoperative recurrence rate is as high as $20.00 \%$, it is no longer the mainstream operation ${ }^{[13]}$. Pterygium excision combined with autogenous conjunctival flap transplantation, the method is to remove the head and neck of pterygium tissue, at the same time, the conjunctival tissue of the eye is repaired and sutured. The postoperative recurrence rate is as high as $46.15 \%$, but it is still widely used by county-level grassroots units in China ${ }^{[14]}$. Pterygium excision combined with amniotic membrane transplantation is to cover the exposed scleral wound of pterygium tissue with amniotic membrane (biological amniotic membrane or fresh amniotic membrane) ${ }^{[15]}$. It is usually used in pterygium surgery, the postoperative recurrence rate is about $8.89 \%$, if combined with mitomycin (mitomycin-C, MMC), but the recurrence rate decreased to $6.90 \%{ }^{[16]}$. At present, it is widely recognized that the best way of pterygium surgery is pterygium excision combined with limbal stem cell (limbal stem cell, LSC) transplantation, which is characterized by the need to include limbal Vogt palisade tissue. This is the area where limbal stem cells are located[17]. The overall recurrence rate of this procedure is $10.00 \%$. If the recurrence rate of LSC transplantation combined with $\mathrm{MMC}$ is only $0.36 \%$, but the method of collecting grafts including Vogt fence area is more difficult. Excessive destruction of the Vogt palisade may lead to the destruction of limbal stem cells and the growth of pseudo pterygium[18]. Few materials can't play the role of stem cell transplantation, at the same time, there are reports of pterygium combined with MMC caused scleral implantation bed perforation cases, suggesting that the use of MMC should be careful[19].

In this paper, an improvement method of full fasciectomy combined with autologous limbal stem cell sharing transplantation was proposed. The method and effect of the operation were analyzed and discussed. The clinical data of 403 cases (420 eyes) of primary unilateral pterygium were analyzed retrospectively. All patients were operated on by the same operator and used the same drugs after operation. Our aim is to provide a safer and more effective surgical treatment for pterygium.

\section{Methods And Materials}

\section{Clinical data}


Patients who underwent full fasciectomy combined with autologous limbal stem cell sharing transplantation in department of ophthalmology, Second People's Hospital of Yunnan from January 2017 to June 2018 were selected. Case inclusion criteria: patients with primary pterygium located on the nasal side, the pterygium head end grew into the limbus cornea $3-5 \mathrm{~mm}$. The patients with ocular diseases which might affect the recurrence of pterygium were excluded, such as ocular surgery and external injury, corneal contact lens wearing history, tarsal gland dysfunction, blepharitis, trachoma and so on. A total of 403 patients (420 eyes) were included, including 195 males and 208 females, aged 43-74 years, with an average age of $(61.35 \pm 2.15)$ years. All of them were operated by the same operator, using the unified standard fascia full resection combined with autologous limbal stem cell sharing transplantation.

\section{Method Of Operation}

\section{Full excision of pterygium lesion epithelium and its inferior fascia tissue}

The conjunctival sac was washed with $0.05 \%$ type III Aner iodine disinfectant for 1 minute, the eyelid was opened, the needle was injected into the neck of the pterygium, and the lidocaine injection was injected under the conjunctiva. The conjunctiva of the neck and body of the muscle was fully separated from the fascia below it and formed a vesicular uplift (Fig. 1A). A conjunctival arc incision with the length of $4 \mathrm{~mm}$ was performed from the lacrimal caruncle $3 \mathrm{~mm}$. The conjunctiva was cut from the two ends of the arc incision to the junction of the pterygium neck and the limbal cornea, the conjunctiva and the proliferating fascia were fully separated. We should avoid destroying the Tenon capsule on the surface of the sclera, blunt separation of the proliferating fascia tissue on the surface of the sclera, lift the fascia away from the surface of the sclera and cut off the range. The cut range was reached to upper and lower fornix, to medial lacrimal caruncle. The hair follicle-like tissue or yellow orbital fat could be faintly detected in the lacrimal caruncle. The head end of the pterygium was bluntly torn off from the corneal surface until smooth. Do not overburn to stop bleeding on the surface of the sclera (Fig. 1B).

\section{The Skill Of Taking Conjunctiva Transplant Piece}

The superior bulbar conjunctiva was fully exposed, lidocaine injection $0.5 \mathrm{ml}$ was injected under the conjunctiva. Pay attention to the needle position as close to the fornix conjunctiva and located between the conjunctiva and fascia, so that the local bulbar conjunctiva bulge (Fig. 1C). According to the size of the scleral implant bed exposed after pterygium excision, the corresponding thin trapezoidal conjunctival epithelial grafts were taken. Pay special attention to the conjunctival epithelium at the limbus, only the grid area at the blue-white junction of the limbus needed to be separated, and there was no need to enter the transparent corneal zone. This method could ensure that some stem cells from the limbal grille could be taken as seed cells. At the same time, most of the normal structure of the limbal grids have been 
preserved and did not affect the repair of bulbar conjunctiva and limbus, so it was called limbal stem cell sharing (Fig. 1D).

\section{Suture Skills Of Conjunctiva Transplant Piece}

Move the conjunctival transplant piece to the scleral implant bed and note that the conjunctival graft could not be reversed. The limbal area of the conjunctival graft corresponded to the limbus of the implanted bed. (Fig. 1E), then fixed the end of the conjunctival graft with $10-0$ silk thread on the superficial sclera of the angular sclera. The inferior conjunctival transplant piece was fixed in the inferior oblique muscle around the lower part of the eyeball, the upper part was fixed 2-3 mm behind the superior margin of the medial rectus muscle, and the medial side was fixed at the 3-4 $\mathrm{mm}$ after the inferior margin of the medial rectus muscle.

After suture, an arc shallow groove was formed in the lacrimal caruncle to restore the normal shape of the lacrimal caruncle. The main points of suture were the suture of the four corners of transplant piece in place, without subvalvular effusion, and the medial edge of transplant piece hidden in the fold of the lacrimal fossa when the eyeball looked straight ahead (Fig. 1F).

\section{Postoperative Treatment}

After operation, levofloxacin eye drops and sodium hyaluronate eye drops were used to prevent infection and improve ocular surface microenvironment, four times a day. Tobramycin and dexamethasone ophthalmic ointment was also used, qn. Conjunctival sutures were removed under microscope 10 days after operation

\section{Postoperative Testing Items And Methods}

The following examinations were performed before operation and 10 days, 1 month, 3 months and 6 months after operation.
A. Tear film break-up time (BUT).
B. Tear meniscus height (TMH): Take Schirmer test strips, reflex $5 \mathrm{~mm}$ at the marking line, gently place it at the junction of the conjunctival sac. After $5 \mathrm{~min}$, remove the filter paper and measure the wet length. The length $<10 \mathrm{~mm}$ is abnormal.
C. Photographic observation and recording of recurrence, proliferation of conjunctiva and corneal surface scars on the anterior segment of ocular surface fluorescence staining. Grade 1: the appearance of the eyes was not different from that of normal eyes; Grade 2: there was neovascularization in the superficial scleral area of pterygium excision, but it did not grow into the limbus of cornea; Grade 3: on the basis of grade 2, accompanied by proliferation of fibrous tissue, 
but did not invade the cornea; Grade 4: accompanied by proliferation of vascular fibrous tissue invading transparent cornea, that is, real recurrence of pterygium. Proliferative scar of conjunctival tissue: Grade 1: The conjunctival tissue of the surgical area was flat and there was no proliferative scar; Grade 2: The conjunctival scar protruded from the conjunctival surface; Grade 3: The conjunctival scar protruded obviously from the conjunctival surface; Grade 4: Proliferation of fasciomatous scar in surgical area.

D. A survey of surgical patients' conscious symptoms and satisfaction with appearance. Grade 1: No subjective symptoms such as foreign body sensation, photophobia and tears; Grade 2: The above mild symptoms; Grade 3: the above symptoms are obvious.

\section{Statistical analysis}

SPSS22.0 software was used for statistical processing. T-test was used for measurement data, $P<0.05$ showed that the difference was statistically significant.

\section{Results}

\section{Tear film breakup time before and after operation}

BUT in each period after operation was longer than that before operation, and the difference was statistically significant $(P<0.05)$, but there was no significant difference in BUT time among different periods after operation $(P>0.05)$. (Tables 1,2$)$

Table 1

Comparison of BUT before and after operation.

\begin{tabular}{|lll|}
\hline & BUT & P \\
\hline Preoperative & $6.10 \pm 0.09$ & - \\
\hline 10 days after operation & $7.00 \pm 0.15$ & $<0.001$ \\
\hline 1 month after operation & $7.02 \pm 0.09$ & $<0.001$ \\
\hline 3 months after operation & $7.00 \pm 0.11$ & $<0.001$ \\
\hline 6 months after operation & $7.12 \pm 0.10$ & $<0.001$ \\
\hline
\end{tabular}


Table 2

Comparison of BUT in different periods after operation.

\begin{tabular}{|llllll|}
\hline $\mathbf{P}$ & $\begin{array}{l}\text { pre } \\
\text { operation }\end{array}$ & $\begin{array}{l}\text { 10 days after } \\
\text { operation }\end{array}$ & $\begin{array}{l}\text { 1 month after } \\
\text { operation }\end{array}$ & $\begin{array}{l}\text { 3 months after } \\
\text { operation }\end{array}$ & $\begin{array}{l}6 \text { months after } \\
\text { operation }\end{array}$ \\
\hline pre-operation & - & $<0.001$ & $<0.001$ & $<0.001$ & $<0.001$ \\
\hline $\begin{array}{l}10 \text { days after } \\
\text { operation }\end{array}$ & $<0.001$ & - & 0.059 & 0.907 & .681 \\
\hline $\begin{array}{l}1 \text { month after } \\
\text { operation }\end{array}$ & $<0.001$ & 0.059 & - & 0.054 & 0.076 \\
\hline $\begin{array}{l}3 \text { months after } \\
\text { operation }\end{array}$ & $<0.001$ & 0.907 & 0.054 & - & 0.769 \\
\hline $\begin{array}{l}6 \text { months after } \\
\text { operation }\end{array}$ & $<0.001$ & 0.681 & 0.076 & 0.769 & - \\
\hline
\end{tabular}

Table 3

Number of eyes with normal and abnormal TMH before and after operation.

\begin{tabular}{|lllll|}
\hline & Normal & Abnormal & Summation & Abnormal rate \\
\hline Pre-operation & 374 & 46 & 420 & $10.95 \%$ \\
\hline 10 days after operation & 369 & 51 & 420 & $12.14 \%$ \\
\hline 1 month after operation & 376 & 44 & 420 & $10.47 \%$ \\
\hline 3 months after operation & 373 & 47 & 420 & $11.19 \%$ \\
\hline 6 months after operation & 378 & 42 & 420 & $10 \%$ \\
\hline Total & 2290 & 230 & 2520 & $9.1 \%$ \\
\hline
\end{tabular}

\section{Tear Meniscus Height (tmh) Before And After Operation}

There was no significant difference in the number of eyes with normal and abnormal TMH before and after operation $(P>0$ 05).

\section{Observation Index Of Terminal Follow-up Period}

Comparison of pterygium recurrence, conjunctival tissue proliferation scar and subjective symptoms before and after operation. The incidence of pterygium recurrence was low and the patients were satisfied with the appearance of pterygium during the final follow-up period ( 6 months after operation). There were no obvious subjective symptoms such as foreign body sensation, photophobia and tears. (Table 4) 
Table 4

Observation index of terminal follow-up period.

\begin{tabular}{|lllll|}
\hline Observation index & \multicolumn{3}{c|}{ Grade } & \\
\hline Recurrence & Grade 1 & Grade 2 & Grade 3 & Grade 4 \\
\cline { 2 - 5 } & $\begin{array}{l}95.47 \% \\
(401 / 420)\end{array}$ & $\begin{array}{l}3.57 \% \\
(15 / 420)\end{array}$ & $\begin{array}{l}0.71 \% \\
(3 / 420)\end{array}$ & $0.21 \%$ \\
& Grade 1 & Grade 2 & Grade 3 & Grade 4 \\
\hline $\begin{array}{l}\text { Proliferative scar of conjunctival } \\
\text { tissue }\end{array}$ & $\begin{array}{l}94.04 \% \\
(398 / 420)\end{array}$ & $\begin{array}{l}3.80 \% \\
(16 / 420)\end{array}$ & $0.71 \%$ & $0.71 \%$ \\
& & & & $(3 / 420)$ \\
Subjective symptom & Grade 1 & Grade 2 & Grade 3 & \\
\cline { 2 - 5 } & $90.47 \%$ & $7.61 \%$ & $1.90 \%$ & \\
& $(380 / 420)$ & $(32 / 420)$ & $(8 / 420)$ & \\
\cline { 2 - 5 } & & & & \\
\hline
\end{tabular}

\section{Comparison of anterior segment photos}

Slit lamp anterior segment photos between left eye and right eye, pre-operation and 10 days, 3 months, 6 months after operation. (Fig. 2)

\section{Discussion And Conclusion}

Postoperative recurrence of pterygium has been the biggest problem for clinicians and patients. Repeated recurrence and surgery are bound to seriously damage the ocular surface structure, visual acuity, conjunctival sac stenosis, symblepharon and other serious complications[20]. The selection and manipulation of operation is the key to determine the recurrence of pterygium after operation. The new operative method introduced in this paper is helpful to further reduce the recurrence rate after operation. In clinical cases, we observed that recurrent pterygium often began to proliferate from the lacrimal fossa, pulling the conjunctiva and blood vessels into the head in the shape of a bundle, considering that the fascia tissue of the lacrimal fossa might be the starting site of postoperative recurrence[21]. Because the conjunctiva and fascia tissue of the lesion site of pterygium was most likely to remain here, and loosed connective tissue containing a large number of fibroblasts and rich capillaries, some of the fibroblasts might come from epithelial cells that underwent the conversion from epithelial cells to mesenchymal cells (epithelial-mesenchymal transition, EMT)[10, 22]. Therefore, we carried out very serious and meticulous removal of pterygium tissue and its inferior fascia tissue during the operation until the lacrimal fossa tissue and a small amount of adipose tissue were exposed. The connective fascia tissue containing a large number of fibroblasts and capillaries was removed to the greatest extent, and a superficial arc 
groove was formed in the lacrimal fossa during suture, which further blocked the proliferation of fascia. The recurrence of pterygium caused by residual fascia tissue hyperplasia was greatly reduced.

Stem cells should be taken from limbal tissue within 6 clock bits in order to avoid limbal stem cell deficiency in donor site[23]. In this paper, all conjunctival grafts are taken from the upper conjunctiva, the range is not more than 2 clock positions, and the front end of the graft reaches the end of the anterior elastic layer of the limbal vascular network. This method can ensure that part of the limbal grille tissue is taken as the seed cells of limbal stem cells, while retaining most of the normal structure of the limbal grille area, and does not affect the repair of bulbar conjunctiva and limbus in the sampling area. Therefore, it is called limbal stem cell sharing.

Postoperative pterygium may cause and aggravate dry eye symptoms, bring discomfort to patients, seriously affect the quality of life, and may affect the uniform coating of tear film with conjunctival tissue scar and relaxation after pterygium operation. Turkyilmaz [24] et al. compared the results of dry eye examination between 24 cases of recurrent pterygium after simple scleral resection and 50 cases of nonrecurrent pterygium. It was found that the postoperative tear osmotic pressure was significantly improved in both groups. The tear osmotic pressure decreased after 12 months of pterygium recurrence. The authors infer that pterygium excision can improve tear film function.

Our 403 cases (420 eyes) were investigated before operation and 10 days, 1 month, 3 months and 6 months after operation. BUT, TMH, slit lamp photography and patients' conscious symptoms and appearance satisfaction were investigated. The results showed that the average preoperative BUT was $6.10 \pm 0.09 .7 .00 \pm 0.15,7.02 \pm 0.09,7.00 \pm 0.11$ and $7.12 \pm 0.10$ at 10 days, 1 month, 3 months and 6 months after operation, respectively.

The average value of BUT in each time period after operation was longer than that before operation, which indicated to the stability of tear film after operation was better than that before operation. The conjunctival graft of limbal stem cells was thin and smooth, and the method of close fitting and stable suture and fixation with scleral surface was beneficial to the recovery of ocular surface structure and increased the stability of lacrimal film. The abnormal rate of TMH was $10.95 \%$ before operation, $12.14 \%$, $10.47 \%, 11.19 \%$ and $10 \%$ at 10 days, 1 month, 3 months and 6 months after operation, respectively. There was no significant difference in the number of eyes with normal and abnormal Slt before and after operation. The results showed that this operation had no clear effect on lacrimal secretion, and did not reflex increase the amount of lacrimal secretion due to postoperative inflammatory reaction and ocular discomfort caused by scar formation. The recurrence, scar proliferation of conjunctiva and corneal surface were observed and recorded by slit lamp photography. $95.47 \%$ of the patients had no difference between the appearance of postoperative eyes and normal eyes (recurrence index Grade 1). Only 1 case had vascular fibrous tissue hyperplasia invading transparent cornea, the recurrence rate of real pterygium (Grade 4) was $0.21 \%$.

$94.04 \%$ of the patients had smooth conjunctival tissue and no proliferative scar (Grade I). Fasciomatous scar proliferation was found in $0.71 \%$ of the patients ( 3 cases). $90.47 \%$ of the patients had no subjective 
symptoms such as foreign body sensation, photophobia and tears after operation, $7.16 \%$ of the patients had mild symptoms, and $1.09 \%$ of the patients had obvious symptoms.

We can conclude that full fasciectomy combined with autologous limbal stem cell sharing transplantation is a very good surgical method for the treatment of pterygium. Its advantages include a very low postoperative recurrence rate $(0.21 \%)$, which is lower than the current statistical recurrence rate $(0.36 \%)[25,26]$. From the aspects of postoperative BUT, slt, patients' conscious symptoms and appearance satisfaction, it has great advantages. The increase of postoperative tear film stability is beneficial to reduce the recurrence rate and symptoms of postoperative dry eyes, and at the same time, the postoperative appearance effect is satisfactory. It is also a very suitable choice for patients with beauty needs.

\section{Declarations}

\section{Ethics approval and consent to participate}

This report was approved by the ethics committee at The Second People's Hospital of Yunnan province. The patient's legal guardian gave written, informed consent prior to undergoing this study.

\section{Consent for publication}

The risk of identification of the patient was minimized and the case patient's legal guardian gave written, informed consent for publication of this report.

\section{Availability of data and materials}

All data generated or analyzed in this report are included in this published article.

\section{Funding}

This study was supported by the Major science and technology projects in Yunnan province (2018ZF009), Yunnan health science and technology plan project (2018NS0012). The eye disease clinical medical research center of Yunnan province (YJZX-2019007). They supported the data collection, interpretation and writing manuscript.

\section{Authors' contributions}

ZWJ, HZL, KL designed and conducted the study. ZWJ, HZL, KL, LH, LY, KHQ, ZQ, WYT provided clinical care. ZWJ, FXX, YJ and HZL analyzed and interpreted the patient data. ZWJ, HZL, and KL were major contributors in writing the manuscript. All authors read and approved the final manuscript.

\section{Competing interests}

The authors declare no conflict of interest.

\section{Acknowledgments}

We appreciate all patients for their participation in this study. 


\section{References}

1. Gonnermann J, Maier AK, Klein JP, Bertelmann E, Pleyer U, Klamann MK: Evaluation of ocular surface temperature in patients with pterygium. Current eye research 2014, 39(4):359-364.

2. Saw SM, Tan D: Pterygium: prevalence, demography and risk factors. Ophthalmic Epidemio/1999, 6(3):219-228.

3. Gazzard G, Saw SM, Farook M, Koh D, Widjaja D, Chia SE, Hong CY, Tan DT: Pterygium in Indonesia: prevalence, severity and risk factors. The British journal of ophthalmology 2002, 86(12):1341-1346.

4. Li J, Zhong H, Cai N, Luo T, Li J, Su X, Li X, Qiu X, Yang Y, Yuan Y et al: The prevalence and causes of visual impairment in an elderly Chinese Bai ethnic rural population: the Yunnan minority eye study. Investigative ophthalmology \& visual science 2012, 53(8):4498-4504.

5. Liu H, Yang J, Zhong L: [Prevalence survey on pterygium in two counties of Hainan Province]. Zhonghua Yan Ke Za Zhi 2001, 37(1):21-23.

6. Ha SW, Park JH, Shin IH, Kim HK: Clinical analysis of risk factors contributing to recurrence of pterygium after excision and graft surgery. International journal of ophthalmology 2015, 8(3):522527.

7. Palamar M, Degirmenci C, Ertam I, Yagci A: Tear Osmolarity and Tear Film Parameters in Patients With Ocular Rosacea. Eye Contact Lens 2016, 42(6):401.

8. Julio G, Lluch S, Pujol P, Dolores Merindano M, Soledad Marques-Calvo M: Conjunctival Short-term Evolution after Pterygium Excision. Optom Vis Sci 2015, 92(7):790-795.

9. Zhong H, Chen Q, Li J, Shen W, Sheng X, Niu Z, Zhou H, Wei T, Yuan Y, Pan CW: Ethnic Variations in Pterygium in a Rural Population in Southwestern China: The Yunnan Minority Eye Studies. Ophthalmic Epidemiol 2016, 23(2):116-121.

10. Bianchi E, Scarinci F, Grande C, Plateroti R, Plateroti P, Plateroti AM, Fumagalli L, Capozzi P, Feher J, Artico M: Immunohistochemical profile of VEGF, TGF-beta and PGE(2) in human pterygium and normal conjunctiva: experimental study and review of the literature. Int $\mathrm{J}$ Immunopathol Pharmacol 2012, 25(3):607-615.

11. Murube J: Pterygium: evolution of medical and surgical treatments. Ocul Surf 2008, 6(4):155-161.

12. Kheirkhah A, Hashemi H, Adelpour M, Nikdel M, Rajabi MB, Behrouz MJ: Randomized Trial of Pterygium Surgery with Mitomycin C Application Using Conjunctival Autograft versus ConjunctivalLimbal Autograft. Ophthalmology 2012, 119(2):227-232.

13. Koranyi G, Seregard S, Kopp ED: The cut-and-paste method for primary pterygium surgery: long-term follow-up. Acta ophthalmologica 2010, 83(3):298-301.

14. Koranyi G, Seregard S, Kopp ED: Cut and paste: a no suture, small incision approach to pterygium surgery. British Journal of Ophthalmology 2004, 88(7):911.

15. Franzco RWE, Franzco GRS, Franzco MD, Frcophth DMT: Amniotic membrane grafting in the surgical management of primary pterygium. Clinical \& Experimental Ophthalmology 2010, 32(5):501-504. 
16. Rubinfeld RS, Pfister RR, Stein RM, Foster CS, Martin NF, Stoleru S, Talley AR, Speaker MG: Serious complications of topical mitomycin-C after pterygium surgery. Ophthalmology 1992, 99(11):16471654.

17. Wang HM: Corneal limbal epithelial stem cell auto transplantation for treating pterygium in 78 cases. International journal of ophthalmology 2005.

18. Fakhry MA: The use of mitomycin $\mathrm{C}$ with autologous limbal-conjunctival autograft transplantation for management of recurrent pterygium. Clinical ophthalmology 2011, 2011(default):123.

19. Rubinfeld RS, Pfister RR, Stein RM, Foster CS, Martin NF, Stoleru S, Talley AR, Speaker MG: Serious complications of topical mitomycin-C after pterygium surgery. Ophthalmology 1992, 99(11):16471654.

20. Jürgenliemkschulz IM, Hartman LJ, Roesink JM, Tersteeg RJ, Van DTI, Kal HB, Mourits MP, Wyrdeman HK: Prevention of pterygium recurrence by postoperative single-dose beta-irradiation: a prospective randomized clinical double-blind trial. International Journal of Radiation Oncology Biology Physics 2004, 59(4):1138-1147.

21. Hirst LW: Recurrent pterygium surgery using pterygium extended removal followed by extended conjunctival transplant: recurrence rate and cosmesis. Ophthalmology 2009, 116(7):1278-1286.

22. Wu CW, Peng ML, Yeh KT, Tsai YY, Chiang CC, Cheng YW: Inactivation of p53 in pterygium influence miR-200a expression resulting in ZEB1/ZEB2 up-regulation and EMT processing. Experimental eye research 2016, 146:206-211.

23. Das P, Gokani A, Bagchi K, Bhaduri G, Chaudhuri S, Law S: Limbal epithelial stemmicroenvironmental alteration leads to pterygium development. Molecular \& Cellular Biochemistry 2015, 402(1-2):123-139.

24. Türkyılmaz K, Oner V, Sevim MŞ, Kurt A, Sekeryapan B, Durmuş M: Effect of pterygium surgery on tear osmolarity. Journal of Ophthalmology 2013, 2013:863498.

25. Sarnicola V, Vannozzi L, Motolese PA: Recurrence rate using fibrin glue-assisted ipsilateral conjunctival autograft in pterygium surgery: 2-year follow-up. Cornea 2010, 29(11):1211-1214.

26. Koh YM, Kim JY, Ji NC: A Comparative Study of Recurrence Rate in Bilateral Pterygium Surgery: Conjunctival Autograft Transplantation Versus Bare Scleral Techinque. 2001.

\section{Figures}



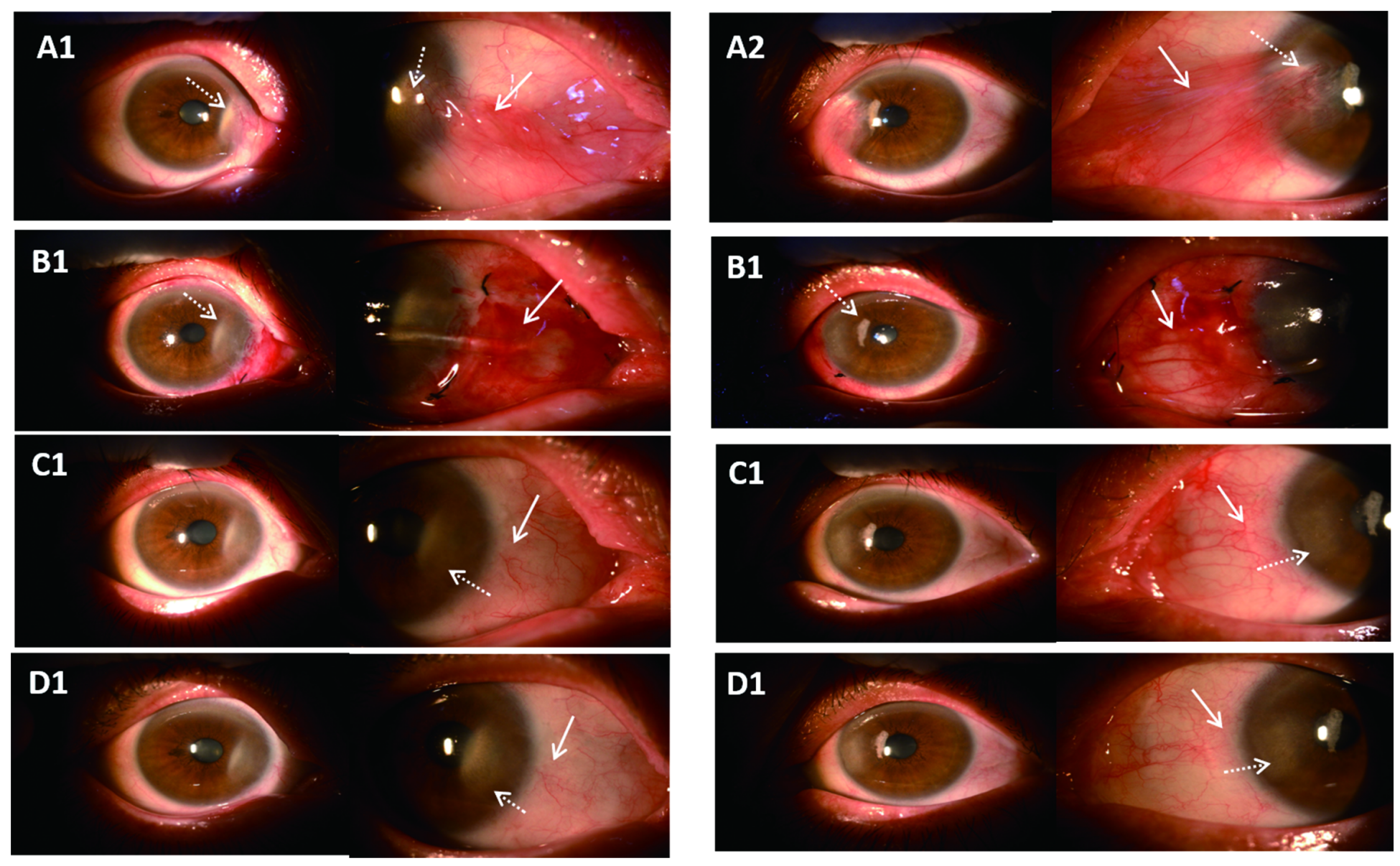

\section{Figure 1}

Surgical procedure schematic diagram. (A) Subconjunctival injection of lidocaine into the neck and body to form a conjunctival vesicular eminence (white arrow). (B) A conjunctival arc incision with length of $4 \mathrm{~mm}$ was performed, $3 \mathrm{~mm}$ from lacrimal caruncle. The conjunctiva and its inferior fascia were fully separated and the proliferating fascia was removed (solid line arrow). The clean scleral implant bed (dashed line arrow) was exposed. (C) Injected lidocaine into the upper bulbar conjunctiva to make the local conjunctiva bulge (arrow). (D)According to the size of scleral implantation bed, thin trapezoidal conjunctival epithelial grafts (dashed lines) were taken out by. Note that when taking the conjunctival epithelium from the limbus, only the grid area at the blue-white junction of the limbus needs to be separated, and there is no need to enter the transparent corneal zone (arrow). (E) Translate the conjunctival flap to the scleral implant bed to ensure that the epithelium is on the top, and the limbal area of the conjunctival graft corresponds to the limbal area of the implant bed (arrow). (F) Fixed the conjunctival graft with 10-0 silk thread, and the graft piece was flat and without subvalvular effusion (long arrow). After suture, a curved shallow groove could be formed in the lacrimal caruncle and the normal shape of the lacrimal caruncle could be restored. When the eyeball looked straight ahead, the medial edge of the graft was hidden in the fold of the lacrimal fossa (short arrow). 

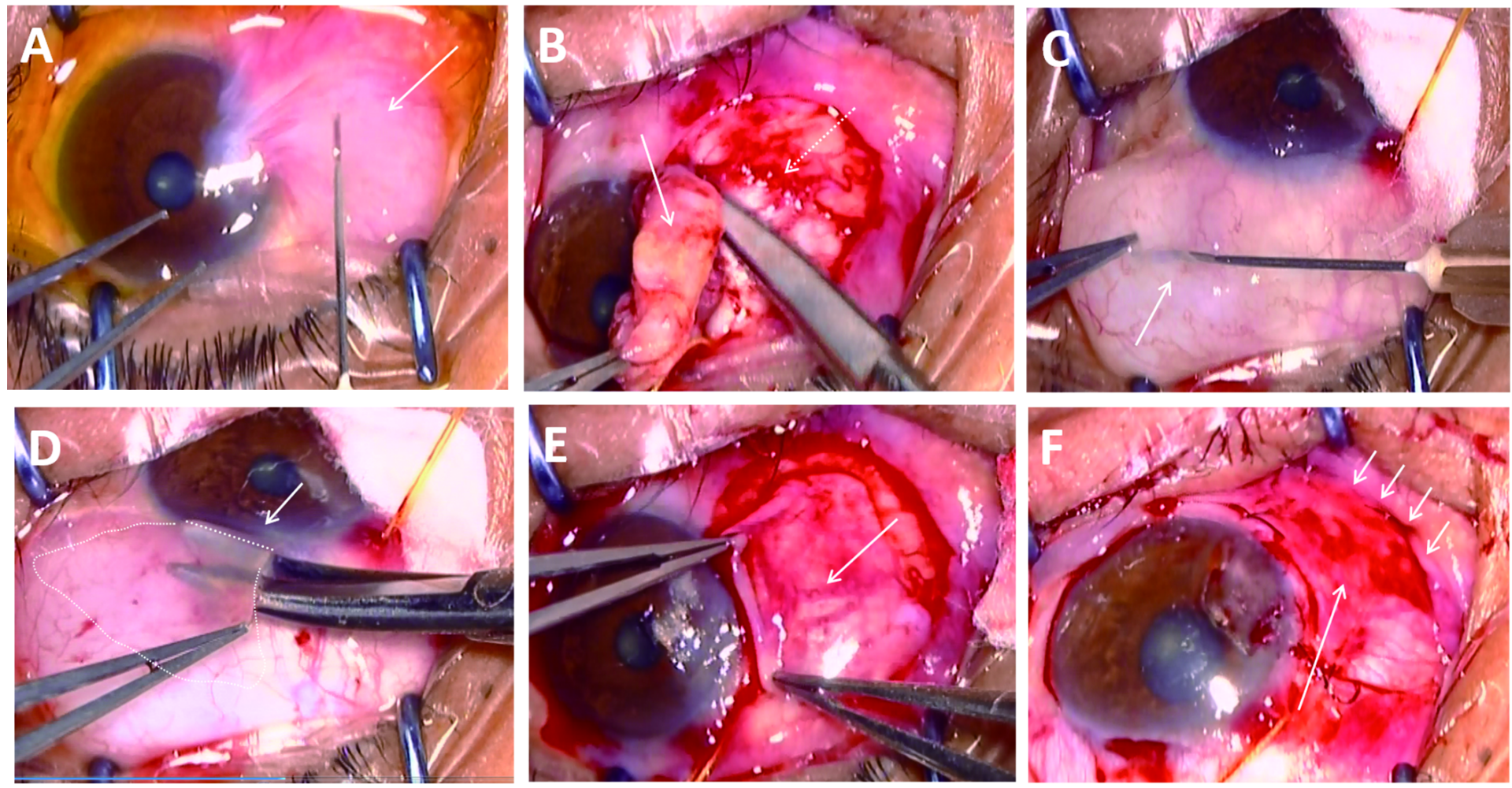

\section{Figure 2}

Photos of anterior segment under slit lamp before and after operation. (A1, A2) The pterygium tissue of right eye (A1) and left eye (A2) showed thick cord with thick vascular bundle (solid line arrow), and the head end of pterygium infiltrated into the anterior corneal stroma layer into grayish white (dashed line arrow). (B1, B2) 10 days after operation, the conjunctival graft with limbal stem cells was tightly attached to the implant bed, no exudate (solid line arrow) was seen below the graft, and the epithelium of the infiltrated part of the cornea grew smoothly and returned to a certain degree of transparency (dotted line arrow). (C1, C2) 3 months after operation, the conjunctiva was smooth and flat, and the boundary of the conjunctival graft (solid line arrow) could not be seen. (D1, D2) 6 months after operation, the conjunctiva was smooth and without hyperemia and vascular hyperplasia (solid line arrow). No surgical marks were seen on the front, the corneal nebula did not change, and the cornea showed smooth. 